\title{
The first assessment to detect Mycoplasma hyopneumoniae by sampling laryngeal swabs to investigate sow stability in South Korea
}

\author{
YuSik Oh ${ }^{1,2}$, JongHyuk Baek ${ }^{3}$, JoongBok Lee ${ }^{2}$, Sun-Hee $\mathrm{Cho}^{3}$ and Changhoon Park ${ }^{4^{*}}$ (D)
}

\begin{abstract}
Background: Mycoplasma hyopneumoniae (M. hyopneumoniae), a representative pathogen causing swine enzootic pneumonia, generally infects piglets vertically. However, it is difficult to ascertain the M. hyopneumoniae infection state of sows due to limited detection methods. This report investigated sow herd stability by applying nested PCR to laryngeal swabs of suckling pigs, which is reportedly the most sensitive method.

Results: M. hyopneumoniae was detected in 14 farms (63.6\%) and 127 piglets (6.5\%). The prevalence of sows likely to transmit M. hyopneumoniae in herds (11.1\%) was calculated. In addition, there was a significant difference in detection rates among farms depending on herd size, gilt replacement rate, acclimation method, and antibiotic usage, suggesting various parameters that influence sow stability.

Conclusions: The results demonstrated that laryngeal swabs from suckling pigs have provided useful information regarding vertical transmission from sows in South Korean farm conditions. This result demonstrated that farms with larger herd sizes, higher gilt replacement rates, and a practice of naturally exposing gilts for acclimation had higher detection rates in weaning piglets, indicating an unstable sow infection state.
\end{abstract}

Keywords: Mycoplasma hyopneumoniae, Laryngeal swab, Vertical transmission, Herd size, Acclimation

\section{Background}

Swine enzootic pneumonia (EP), a chronic respiratory disease in pigs of all ages characterized by dry coughing, growth retardation, and poor feeding efficiency, is mainly caused by M. hyopneumoniae [1]. M. hyopneumoniae adheres to the ciliated epithelium of the respiratory tract of the pig. After attachment, the infected pigs show chronic coughing and increased susceptibility to other respiratory infections. Due to these symptoms, the pigs have reduced weight gain [2]. In some cases, other

\footnotetext{
* Correspondence: votongnum@naver.com

${ }^{4}$ Department of Microbiology and Immunology, Eulji University School of Medicine, Yongdu-dong, Jung-gu, Daejeon, South Korea

Full list of author information is available at the end of the article
}

species of Mycoplasma, such as M. hyorhinis or M. hyosynoviae, are also able to infect pigs. M. hyorhinis commonly causes polyserositis and arthritis in nursery pigs. $M$. hyosynoviae causes arthritis in grower-finishers [3]. However, the tremendous economic loss in the swine industry was caused by $M$. hyopneumoniae due to decreased performance, increased treatment and vaccination costs [4].

Swine enzootic pneumonia caused by infection with M. hyopneumoniae is one of the most common diseases on pig farms worldwide. Several abattoir surveys have demonstrated that a high prevalence of enzootic pneumonia is associated with lung lesions in pigs [5-7]. In South Korea, antibodies against $M$. hyopneumoniae were

C C The Author(s). 2020 Open Access This article is licensed under a Creative Commons Attribution 4.0 International License, which permits use, sharing, adaptation, distribution and reproduction in any medium or format, as long as you give appropriate credit to the original author(s) and the source, provide a link to the Creative Commons licence, and indicate if changes were made. The images or other third party material in this article are included in the article's Creative Commons licence, unless indicated otherwise in a credit line to the material. If material is not included in the article's Creative Commons licence and your intended use is not permitted by statutory regulation or exceeds the permitted use, you will need to obtain permission directly from the copyright holder. To view a copy of this licence, visit http://creativecommons.org/licenses/by/4.0/ The Creative Commons Public Domain Dedication waiver (http://creativecommons.org/publicdomain/zero/1.0/) applies to the data made available in this article, unless otherwise stated in a credit line to the data. 
mainly detected in pigs $14-22$ weeks old [8]. In another report, $67.8 \%$ of the collected oral fluid samples and $87.5 \%$ of the investigated farms were polymerase chain reaction (PCR) positive in the country [9].

Vertical transmission of $M$. hyopneumoniae from an infected sow to her piglets is recognized as the typical pathway of enzootic pneumonia. Infected sows are considered a risk factor for M. hyopneumoniae infection in the preweaning period [10]. M. hyopneumoniae shedding through direct contact with vertically infected piglets is the initial infection source in susceptible pig populations during the nursery and growth-finishing periods [10]. "Sow herd stability" has been described as an absence of clinical signs and no evidence of pathogen circulation within the sow herd. Generally, sow herd stability is thought to be directly linked to the entire herd stability due to vertical transmission. The proportion of positive piglets in each weaning group was correlated with the proportion of positive sows in the group. Therefore, in terms of sow stability, the source of gilts, herd size, stocking density, and ventilation system are the main important risk factors for enzootic pneumonia linked to M. hyopneumoniae [11-13].

For conclusive diagnosis, culturing of M. hyopneumoniae has been considered the gold standard. However, it is not used for routine diagnosis due to the highly timeconsuming process. The organism can also be detected by immunofluorescence testing, but the test has limited sensitivity. Although serology can be used to show the presence of M. hyopneumoniae at a herd level, it is not proper for diagnosis on individual animals [14]. Currently, nested PCR testing has been demonstrated as the most sensitive tool to detect extremely low levels of nucleic acids [15]

A recent study indicated that laryngeal swabs investigated with the PCR method are superior in detecting early $M$. hyopneumoniae infection compared to the more commonly used investigation of nasal swabs and tracheobronchial lavage fluid in eight-week-old pigs [16]. PCR results for laryngeal swab samples had the highest sensitivity of all sample types at 5 days after infection, with a detection rate of $81 \%$. The present study aimed to investigate the sow herd stability of $M$. hyopneumoniae using laryngeal swabs of suckling pigs. Although M. hyopneumoniae is barely detected in adult pigs, the detection rate of weaning pigs that were vertically infected by sows was comparably high. This is the first report of infection and virus shedding among sows in South Korean field conditions, and it was conducted by testing the laryngeal samples of weaning piglets with nested PCR.

\section{Methods}

\section{Farms}

Twenty-two pig farms in South Korea were selected for testing. To investigate the test, swine veterinarians visited 22 farms under the contract. Without consideration of specific geological area, the veterinarians selected 22 farms according to pig population from four representative swine producing provinces of South Korea (three farms in Gyeonggi-do (19\% of the total national pig population); eight farms in Chungcheong-do (28\%); six farms in Jeolla-do (25\%); five farms in Gyeongsang-do (23\%)). Accordingly, the farms were distributed in balance across the nation.

The farms had a higher number of marketed pigs per sow per year (MSY) than the average South Korean pig farm and were managed with a three-way cross breeding program (Duroc, Landrace, Yorkshire). The average MSY in South Korea was reportedly 17.9 in 2018 based on the Korean pork producer association. The average MSY of 22 farms joined in this study was 21.8. Only three farms (no. 15, 16, and 17) had less MSY than 20. Farm no.15 and 17 had unexpected events including porcine reproductive and respiratory syndrome (PRRS) and porcine epidemic diarrhea (PED) outbreak a year before the experiment. Farm no.16 had a sudden change of gilt source. Their relatively low MSY might result from such internal factors.

All farms had farrow-to-finish production systems and weaned their piglets at three to four weeks of age, while each farm had individual acclimation, antibiotics, and gilt replacement protocols (Table 1). The exposure method to naturally expose the gilts to $M$. hyopneumoniae for acclimation was selected on three farms, and vaccination with commercial products (Ingelvac MycoFLEX and Zoetis Respisure ONE ) was used on 14 farms. While investigating, antibiotics (amoxicillin, enrofloxacin, tilmicosin, ceftiofur, penicillin, streptomycin, gentamicin, tulathromycin, lincomycin, and spectinomycin) were used. In the case of antibiotics, there were three categories associated with the treatment. The sows and growing pigs were inoculated with antibiotics on randomly selected farms: only growing pigs on seven farms, only sows on five farms, and both on six farms. In the case of gilt introduction, seven farms introduced gilts from their own female pigs, and 15 farms brought gilts from grandparent farms (GP). Their protocols are usually used in South Korean swine production systems.

The veterinarians reported signs of porcine respiratory disease complex (PRDC) in growing pigs based on previous tests, which were performed to monitor the herd disease state at least 1 month prior to this experiment. The antibodies against $M$. hyopneumoniae from randomly collected sera were detected by ELISA (BioCheck), and PCR results of necropsied lung tissue showed the presence of $M$. hyopneumoniae. Including $M$. hyopneumoniae, type 1 and type 2 PRRSV, porcine circovirus type 2d (PCV2d) and bacteria (Salmonella, Streptococcus suis) were also isolated from some cases. 
Table 1 Overview of farm management and M. hyopneumoniae detection in piglets

\begin{tabular}{|c|c|c|c|c|c|c|c|c|c|c|}
\hline $\begin{array}{l}\text { Farm } \\
\text { no. }\end{array}$ & $\mathrm{MSY}^{\mathrm{a}}$ & $\begin{array}{l}\text { Herd } \\
\text { size }^{b}\end{array}$ & $\begin{array}{l}\text { Gilt } \\
\text { replication } \\
\text { rate }\end{array}$ & 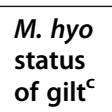 & Gilt source & Acclimation & $\begin{array}{l}\text { Antibiotics } \\
\text { (piglet treatment) }\end{array}$ & $\begin{array}{l}\text { Antibiotics } \\
\text { (Sow treatment) }\end{array}$ & $\begin{array}{l}\text { PRRSV } \\
\text { detection }^{d}\end{array}$ & $\begin{array}{l}\text { M. hyo } \\
\text { prevalence }\end{array}$ \\
\hline & & & & & & & & & & Pos/total \\
\hline 1 & 21 & $\leq 550$ & $\leq 40 \%$ & pos & Self-replacement & $\begin{array}{l}\text { Ingelvac } \\
\text { MycoFLEX }\end{array}$ & & & pos & $7 / 90$ \\
\hline 2 & 20 & $\leq 550$ & $\leq 40 \%$ & pos & Self-replacement & $\begin{array}{l}\text { Ingelvac } \\
\text { MycoFLEX }\end{array}$ & Ceftiofur & & pos & $0 / 90$ \\
\hline 3 & 24 & $\leq 550$ & $>40 \%$ & pos & Self-replacement & Respisure-ONE & $\begin{array}{l}\text { penicillin }+ \\
\text { Streptomycin }\end{array}$ & & neg & $0 / 90$ \\
\hline 4 & 20 & $>550$ & $\leq 40 \%$ & pos & Self-replacement & Respisure-ONE ${ }^{\oplus}$ & Ceftiofur & & pos & $9 / 90$ \\
\hline 5 & 24 & $>550$ & $\leq 40 \%$ & neg & External (GP) & $\begin{array}{l}\text { Ingelvac } \\
\text { MycoFLEX }\end{array}$ & Gentamicin & & pos & $0 / 90$ \\
\hline 6 & 22 & $>550$ & $\leq 40 \%$ & pos & External (GP) & $\begin{array}{l}\text { Ingelvac } \\
\text { MycoFLEX }\end{array}$ & & & pos & $2 / 90$ \\
\hline 7 & 26.5 & $>550$ & $>40 \%$ & pos & External (GP) & Respisure-ONE ${ }^{\oplus}$ & Tulathromycin & & neg & $3 / 88$ \\
\hline 8 & 23 & $>550$ & $>40 \%$ & neg & External (GP) & Exposure & Ceftiofur & Amoxicillin & pos & $6 / 90$ \\
\hline 9 & 25 & $\leq 550$ & $>40 \%$ & neg & External (GP) & None & & & neg & $0 / 90$ \\
\hline 10 & 22 & $\leq 550$ & $\leq 40 \%$ & neg & External (GP) & $\begin{array}{l}\text { Ingelvac } \\
\text { MycoFLEX }\end{array}$ & Tulathromycin & Tiamulin & pos & $5 / 90$ \\
\hline 11 & 20 & $\leq 550$ & $\leq 40 \%$ & pos & Self-replacement & $\begin{array}{l}\text { Ingelvac } \\
\text { MycoFLEX }\end{array}$ & & Tilmicosin & pos & $0 / 90$ \\
\hline 12 & 21 & $>550$ & $>40 \%$ & neg & External (GP) & $\begin{array}{l}\text { Ingelvac } \\
\text { MycoFLEX }\end{array}$ & & Tilmicosin & pos & $0 / 90$ \\
\hline 13 & 23.5 & $>550$ & $>40 \%$ & pos & External (GP) & Respisure-ONE ${ }^{\circ}$ & $\begin{array}{l}\text { Lincomycint } \\
\text { Spectinomycin }\end{array}$ & Amoxicillin & neg & $26 / 90$ \\
\hline 14 & 24.2 & $\leq 550$ & $>40 \%$ & pos & Self-replacement & Exposure & $\begin{array}{l}\text { Lincomycin+ } \\
\text { Spectinomycin }\end{array}$ & & neg & $24 / 90$ \\
\hline 15 & 18 & $\leq 550$ & $\leq 40 \%$ & pos & External (GP) & $\begin{array}{l}\text { Ingelvac } \\
\text { MycoFLEX }\end{array}$ & $\begin{array}{l}\text { Lincomycin+ } \\
\text { Spectinomycin }\end{array}$ & & pos & $0 / 66$ \\
\hline 16 & 16.5 & $>550$ & $\leq 40 \%$ & pos & External (GP) & $\begin{array}{l}\text { Ingelvac } \\
\text { MycoFLEX }\end{array}$ & Tulathromycin & $\begin{array}{l}\text { Lincomycin+ } \\
\text { Spectinomycin }\end{array}$ & pos & $2 / 88$ \\
\hline 17 & 17 & $>550$ & $\leq 40 \%$ & pos & Self-replacement & None & & Amoxicillin & pos & $3 / 90$ \\
\hline 18 & 20 & $>550$ & $\leq 40 \%$ & neg & External (GP) & $\begin{array}{l}\text { Ingelvac } \\
\text { MycoFLEX }\end{array}$ & & Amoxicillin & pos & $13 / 90$ \\
\hline 19 & 22.5 & $>550$ & $>40 \%$ & neg & External (GP) & Exposure & Amoxicillin & $\begin{array}{l}\text { Lincomycin + } \\
\text { Tiamulin }\end{array}$ & pos & $15 / 90$ \\
\hline 20 & 20.3 & $\leq 550$ & $\leq 40 \%$ & pos & External (GP) & None & & Penicillin & pos & $0 / 90$ \\
\hline 21 & 24.3 & $\leq 550$ & $>40 \%$ & neg & External (GP) & None & $\begin{array}{l}\text { Enrofloxacin or } \\
\text { Sulfamethoxazole+ } \\
\text { Trimethoprim }\end{array}$ & Amoxicillin & pos & $11 / 90$ \\
\hline 22 & 25 & $\leq 550$ & $\leq 40 \%$ & neg & External (GP) & None & Ampicillin & & neg & $1 / 90$ \\
\hline
\end{tabular}

${ }^{a}$ Number of pigs, which survive until they reach to the weight for sale and are sold, among pigs produced by a sow for a year

${ }^{b}$ Numbers of sows on individual farms

${ }^{C}$ Anti-M. hyopneumoniae antibody detection results from a previous test

${ }^{\mathrm{d} P R R S V}$ antigen test (PCR) of weanling piglet serum

e Number of positive piglets/total number of piglets tested by nested PCR for M. hyopneumoniae on the three sampling dates pos positive, neg negative

Concretely, 6 farms reported the presence of type 1 PRRSV, and 7 farms reported type 2 PRRSV. Only 3 farms had two PRRSVs simultaneously. PCV2d was the only porcine circovirus type on the farms and was detected on 5 farms. Salmonella and Streptococcus were isolated from one farm.

\section{Laryngeal swab sampling}

Sampling was conducted as previously described [16]. Briefly, a BD CultureSwab ${ }^{\text {tw }}$ Liquid Stuart Single Swab (BD Diagnostics, Sparks, USA) was inserted by a veterinarian right behind the epiglottis of a piglet using a laryngoscope. Two- to three-week-old pigs were randomly 
taken for sampling from at least 15 sows of one farrowing batch, and sampling was performed thrice on each of the 22 farms. The sample size was determined based on the statistical 95\% confidence limit. For the previous data, the detection limit of the positive sample number in the 1000 population was 29. Consequently, 30 samples were needed from each herd.

In most farms, there were $15 \sim 20$ farrowing sows in each batch, and most of them were selected for sampling. There were newborn piglets every week because all farms had the same weekly production system. The test was conducted 1 day per week in three consecutive weeks, and the date was selected by veterinarians during October and November 2018.

\section{M. hyopneumoniae DNA extraction \& nested PCR}

Laryngeal swab samples were processed for DNA isolation with a Viral gene spin RNA/DNA extraction kit (iNtRon Biotechnology, South Korea) on the sampling day, and nested PCR was performed with isolated DNA as previously described [15]. The positive control ( $M$. hyopneumoniae strain SNU98703 culture supernatant) was tested for nested PCR sensitivity. The reaction detected M. hyopneumoniae DNA to a dilution of $10^{-8}$, approximately $1 \mathrm{fg}$, as in a previous report [17]. A pristine swab in DNase and RNase-free water (Sigma-Aldrich, Stockholm, Sweden) was used as the negative control. All nested PCRs were duplicated to confirm the responses.

\section{Statistical analysis}

The chi-square test and Fisher's exact test were used to compare the prevalence of infected piglets with the following parameters: herd size, gilt replacement rate, acclimation procedures, and antibiotic usage. A value of $P<0.05$ was considered significant.

\section{Results}

Detection of $M$. hyopneumoniae DNA

M. hyopneumoniae DNA was detected by nested PCR in 14 farms (63.6\%) and 127 piglets (average 6.5\%, range 028.8\%). After sequencing PCR products, $16 \mathrm{~S}$ ribosomal RNA of M. hyopneumoniae was confirmed. The prevalence of sows likely to transmit $M$. hyopneumoniae (11.1\%) was calculated as the ratio, specifically, the number of sows with $M$. hyopneumoniae-positive piglets divided by the number of total sows. The mean prevalence of $13 \%$ at the first sampling time was reduced to $2.2 \%$ at the final sampling time.

\section{Prevalence of positive piglets with regard to herd size}

M. hyopneumoniae DNA was detected in 48 piglets (5\%) from 11 farms with $\leq 550$ sows and 79 piglets (8\%) from 11 farms with $>550$ sows. Farms with $>550$ sows had a significantly higher detection rate $(P$ value $<0.01)$ (Fig. 1a).

\section{Prevalence of positive piglets with regard to the replacement rate of gilts}

$M$. hyopneumoniae DNA was detected in 42 piglets (4.4\%) from 13 farms that replaced $\leq 40 \%$ of gilts and 85 piglets $(8.6 \%)$ of 9 farms replacing $>40 \%$. Farms replacing $>40 \%$ of gilts had a significantly higher detection rate $(P$ value $=0.0002)$ (Fig. $1 \mathrm{~b})$.

Prevalence of positive piglets with regard to gilt source M. hyopneumoniae DNA was detected in 76 piglets (6.7\%) from 13 farms introducing serologically M. hyopneumoniae-positive gilts and 51 piglets (6.3\%) from nine farms introducing serologically $M$. hyopneumoniae-negative gilts (Fig. 1c). M. hyopneumoniae was detected in 43 piglets $(6.8 \%)$ from seven farms with self-replacement of gilts and in 84 piglets (6.4\%) from 15 farms with gilts brought from grandparent farms (Fig. 1d). There was no significant difference among these farms.

\section{Prevalence of positive piglets with regard to gilt acclimation}

M. hyopneumoniae DNA was detected in 45 piglets (16.7\%) from three farms that naturally exposed gilts to M. hyopneumoniae. M. hyopneumoniae DNA was detected in 67 piglets $(5.4 \%)$ from 14 farms that vaccinated gilts. Finally, M. hyopneumoniae DNA was detected in 15 piglets (3.3\%) from five farms without acclimation treatment. Farms that naturally exposed gilts to $M$. hyopneumoniae had a significantly higher detection rate than the others (P value <0.0001) (Fig. 1e).

\section{Prevalence of positive piglets with regard to usage of antibiotics}

M. hyopneumoniae DNA was detected in 81 piglets (8.2\%) from 11 farms using antibiotics in the sow herds and 46 piglets (4.7\%) from 11 farms that did not (Fig. 1f). The pathogen was detected in 102 piglets (8.3\%) from 13 farms using antibiotics in suckling pigs and 25 piglets (3.4\%) from nine farms that did not. The results showed that the detection rate was significantly higher in farms that used antibiotics in sows or piglets $(P$ value $<0.002)$ (Fig. $1 \mathrm{~g})$.

\section{Discussion}

M. hyopneumoniae is a main causative pathogen of porcine respiratory disease complex (PRDC) [1]. PRDC is characterized clinically by anorexia, slow growth, lethargy, fever, dyspnea and an antibiotic treatment-resistant cough in growing and finishing pigs $[18,19]$. To prevent PRDC, detection of $M$. hyopneumoniae during the early stages of infection is critical but technically challenging. 

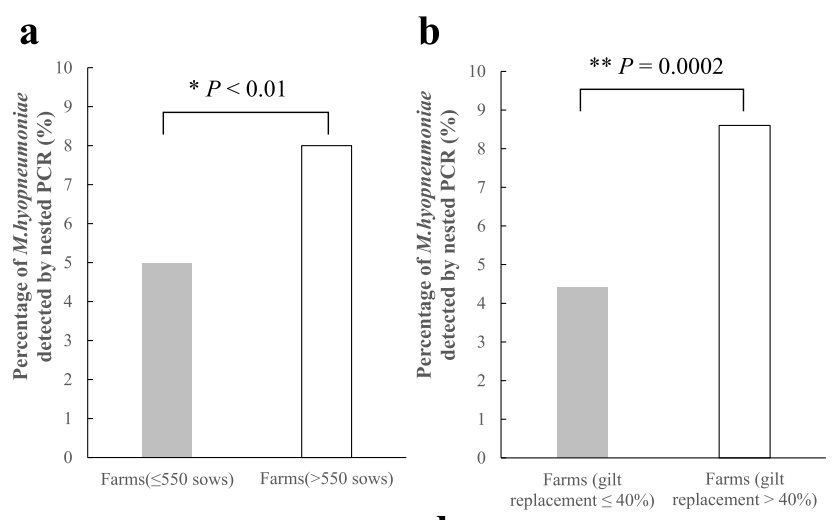

c

d
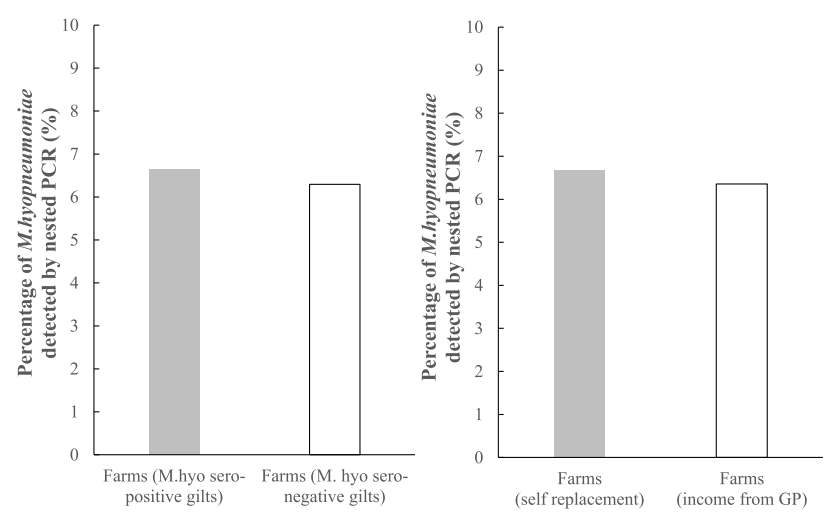

e
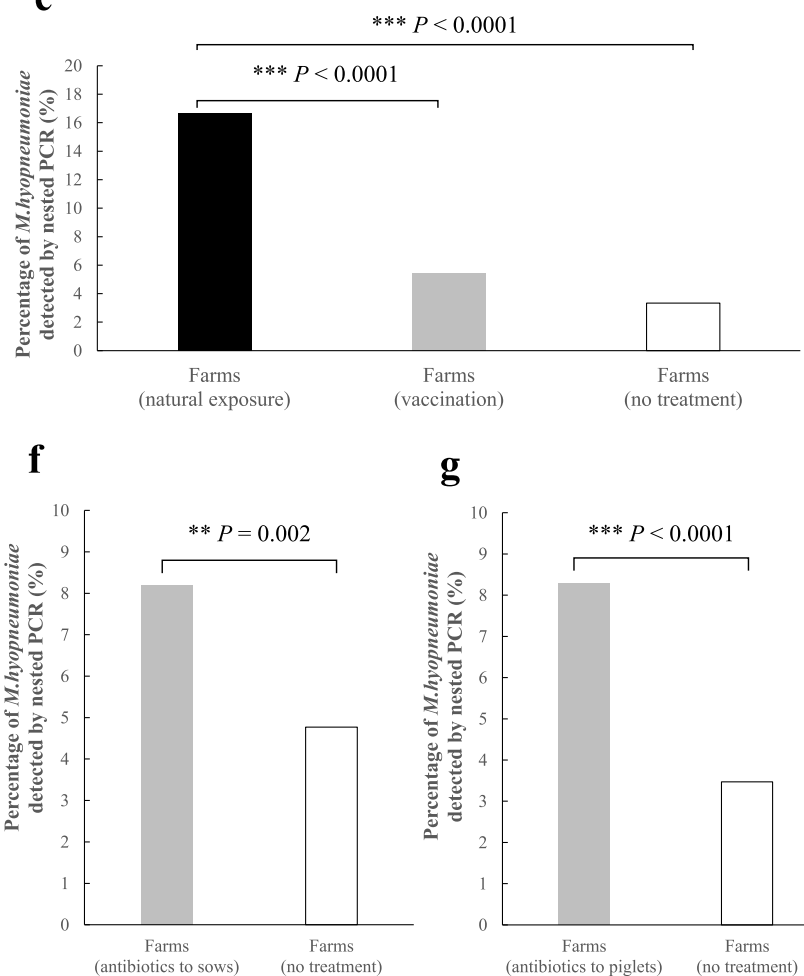

g

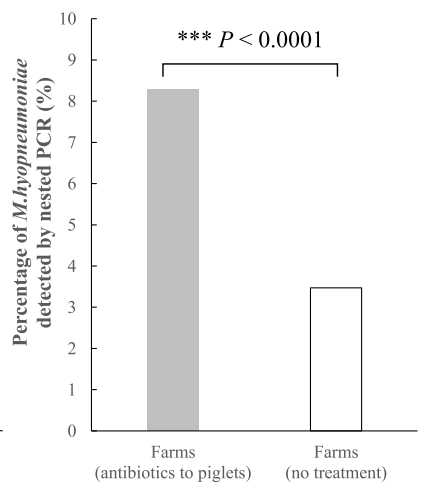

Fig. 1 (See legend on next page.) 
(See figure on previous page.)

Fig. 1 Comparison of the prevalence of $M$. hyopneumoniae between groups. a Comparison of detection rates by herd size: positive piglet prevalence in farms with > 550 sows ( $(\square)$ and others ( $\mathbf{( - )}$. b Comparison of detection rates by gilt replacement rate: prevalence of positive piglets in farms with $>40 \%$ replacement ( $($ ) and others ( $\mathbf{( - )}$. c Comparison of detection rates by gilt status: prevalence of positive piglets in farms introducing serologically positive (- and negative gilts ( $\square)$. $\mathbf{d}$ Comparison of detection rates by gilt source: prevalence of positive piglets in farms that produce their own replacement gilts ( $\mathbf{\square})$ and farms that acquire their gilts from GP ( $\square$ ). e Comparison of detection rates by acclimation method: prevalence of positive piglets in farms that naturally expose gilts to $M$. hyopneumoniae ( $\mathbf{\square})$, farms that vaccinate gilts ( $\mathbf{\square})$, and farms that do not use acclimation treatment ( $\square$ ). $\mathbf{f}$ Comparison of detection rates by antibiotic usage for sows: prevalence of positive piglets in farms that use antibiotics on sows ( $\mathbf{-}$ ) and farms that do not use such treatment ( $\square$ ). $\mathbf{g}$ Comparison of detection rates by antibiotic use on piglets; positive piglet prevalence in farms that use antibiotics on piglets ( $\mathbf{\square})$ and farms that do not use such treatment ( $\square$ )

The colonization of pigs by $M$. hyopneumoniae starts from tracheal cilia as the initial postexposure infection site. Therefore, direct access into the trachea cilia could be useful for sensitive detection of M. hyopneumoniae. And the tracheobronchial lavage fluid may be regarded as the best sample to detect the infected microorganism in this case [20]. However, in previous reports, laryngeal swabs have demonstrated the highest sensitivity for $M$. hyopneumoniae DNA detection among oral, nasal, and tracheobronchial samples as well as antibody detection in serum samples [16, 21, 22]. Although the larynx is not considered the typical location for M. hyopneumoniae infection or colonization, it may function as a vestibular site that may incur lower airways. Consequently, the larynx could be the place where $M$. hyopneumoniae is concentrated, and it is a preferred sampling site for favorable access and proximity to the lower airways [16, 23]. As a field study, our results show that laryngeal swabs for M. hyopneumoniae detection are practical and reliable.

As a result, M. hyopneumoniae DNA was detected by nested PCR in 14 farms (63.6\%) and 127 piglets (average $6.5 \%$, range $0-28.8 \%$ ). The prevalence $(11.1 \%)$ of sows likely to transmit $M$. hyopneumoniae in herds was calculated as the ratio of total sows to sows with pathogenpositive piglets. Compared to previous reports, it was similar to the results obtained in other countries. Using laryngeal swabs, $7 \%$ of weanling pigs and more than $50 \%$ of sow herds tested positive for $M$. hyopneumoniae in the USA. In Germany, $18.7 \%$ of weanling pigs and $75 \%$ of sow herds were PCR positive [24].

There was a significant difference depending on herd size and gilt replacement rate. Farms with more than 550 sows had a significantly higher detection rate than those with lower sow numbers. Farms where more than $40 \%$ gilts were replaced also had a significantly higher detection rate than those where gilts were less replaced. In general, larger farms tend to replace gilts at a higher rate. Larger farms or high gilt replacement rates may support the transmission of pathogens due to management factors such as biosecurity, vaccination practices, and herd density [25]. However, larger farms may have additional factors, such as cross fostering in the farrowing unit, contamination by teeth grinding, tail docking, castration and housing, that have not been investigated in this survey, influencing the results.

There was no significant difference in the prevalence of $M$. hyopneumoniae detection in piglets among farms with regard to the serological status of introduced gilts. Similarly, the detection rate in farms with self-replacing gilts was not significantly different from the rate in farms with gilts brought from grandparent farms. With regard to the long shedding period, sows exposed to $M$. hyopneumoniae at the age of 50-100 days are expected to develop immunity early enough so that the possibility of transmission is reduced at their first farrowing [26].

Notably, farms where gilts were naturally exposed to $M$. hyopneumoniae had a significantly higher detection rate in piglets than farms with vaccinations or without acclimation. Considering that experimentally infected pigs shed M. hyopneumoniae for up to 200 days [27], natural exposure for gilt acclimation at an age of 100 days or older may support vertical transmission. According to the gilt acclimation survey of 22 farms, no farms had diagnostic verification after gilt acclimation. Seventeen farms introduced gilts over 140 days old, and 16 farms had acclimation periods below 10 weeks. Inappropriate acclimation resulted in a high risk of sow stability.

Amoxicillin, enrofloxacin, tilmicosin, ceftiofur, penicillin, streptomycin, gentamicin, tulathromycin, lincomycin, and spectinomycin were used on most farms. Treatments were applied to sows, piglets, or both. Interestingly, the detection rate was significantly higher in farms that used antibiotics in the sow herds than in those that did not use antibiotics. The detection rate was also significantly higher in farms using antibiotics in suckling pigs than in farms where antibiotics were not used. Although antibiotics have been demonstrated to be effective at controlling enzootic pneumonia [28], only limited information is available with regard to the reduction of transmission. It may be interpreted that the farms were facing serious PRDC problems when there was a higher detection rate of $M$. hyopneumoniae in the farms where antibiotics were actively used. Farms with severe enzootic pneumonia outbreaks tend to use 
antibiotics more frequently as a control measure. In addition, the symptoms may reappear after cessation of treatment or development of antimicrobial resistance [2].

As a result of subpopulation in a batch, there was a great deal of variability in the prevalence between farrowing batches within a farm. The mean prevalence at the first sampling time was $13 \%$. In the second sampling time, a mean prevalence of $4.9 \%$ was reported. For the third sampling time, the mean prevalence was $2.2 \%$. These results suggest that the time of infection and shedding of M. hyopneumoniae is not consistent in the different farrowing batches. In addition, a minimum of three sampling time points is necessary to assess sow herd stability. The necessity of multiple samplings has already been suggested [29].

\section{Conclusions}

In summary, this study investigated the difference in $M$. hyopneumoniae prevalence in weaning-age or approximately weaning-age piglets among farms. The results demonstrated that laryngeal swabs of suckling pigs provided useful information with regard to sow herd stability in farms with enzootic pneumonia. In addition, it provided some insight into influencing parameters such as herd size, gilt replacement, acclimation, and antibiotic usage.

\section{Abbreviations}

M. hyopneumoniae: Mycoplasma hyopneumoniae; PCR: Polymerase chain reaction; MSY: Marketed pigs per sow per year; PRDC: Porcine respiratory disease complex

\section{Acknowledgments}

Not applicable.

\section{Authors' contributions}

YSO, JHB, JBL and CP designed and performed the experiments and analyzed the data. YSO, SHC and CP drafted the manuscript. YSO provided the necessary funding. All authors read and approved the final manuscript.

\section{Funding}

This research was supported by Boehringer Ingelheim Animal Health Korea Ltd. The funder had no role in the study design, data collection and analysis, decision to publish, or preparation of the manuscript.

\section{Availability of data and materials}

The dataset collected in the current study is available from the corresponding author upon reasonable request.

\section{Ethics approval and consent to participate}

All the experimental procedures were reviewed and approved by the Ethical Committee of BioPOA Co. Permission was obtained from the veterinarians who participated in this study, and written informed consent was obtained from the farmers.

\section{Consent for publication}

Not applicable.

\section{Competing interests}

No competing interests.

\section{Author details}

${ }^{1}$ Boehringer Ingelheim Animal Health Korea Ltd., Seoul, South Korea. ${ }^{2}$ Department of Infectious Diseases, College of Veterinary Medicine, Konkuk University, Seoul, South Korea. ${ }^{3}$ Department of Animal Vaccine Development, BioPOA, 593-26 Dongtangiheung-ro, Hwaseong-si, Gyeonggi-do, Republic of Korea. ${ }^{4}$ Department of Microbiology and Immunology, Eulji University School of Medicine, Yongdu-dong, Jung-gu, Daejeon, South Korea.

Received: 3 January 2020 Accepted: 30 October 2020

Published online: 23 November 2020

\section{References}

1. Simionatto S, Marchioro B, Maes D, Dellagostin OA. Mycoplasma hyopneumoniae: from disease to vaccine development. Vet Microbiol. 2013; 165:234-42.

2. Maes D, Segales J, Meyns T, Sibila M, Pieters M, Haesebrouck F. Control of Mycoplasma hyopneumoniae infections in pigs. Vet Microbiol. 2008; 126:297-309.

3. Whittlestone P. Porcine mycoplasmas. In: Tully JG, Whitcomb RF, editors. The Mycoplasmas II. Human and Animal Mycoplasmas. New York: Academic Press; 1979. p. 133-76.

4. Maes D, Sibila M, Kuhnert P, Segales J, Haesebrouck F, Pieters M. Update on Mycoplasma hyopneumoniae infections in pigs: Knowledge gaps for improved disease control. Transbound Emerg Dis. 2018:65:110-24.

5. Falk K, Hoie S, Lium BM. An abattoir survey of pneumonia and pleuritis in slaughter weight swine from 9 selected herds. II. Enzootic pneumonia of pigs: microbiological findings and their relationship to pathomorphology. Acta Vet Scand. 1991;32:67-77.

6. Wallgren P, Sahlander P, Hassleback G, Heldmer E. Control of infections with Mycoplasma hyopneumoniae in swine herds by disrupting the chain of infection, disinfection of buildings and strategic medical treatment. J Veterinary Med Ser B. 1993;40:157-69.

7. Wallgren P, Beskow P, Fellstrom C, Renstrom LH. Porcine lung lesions at slaughter and their correlation to the incidence of infections by Mycoplasma hyopneumoniae and Actinobacillus pleuropneumoniae during the rearing period. J Veterinary Med Ser B. 1994;41:441-52.

8. Chae C. Porcine circovirus type 2 and its associated diseases in Korea. Virus Res. 2012;164:107-13.

9. Cheong Y, Oh C, Lee K, Cho KH. Survey of porcine respiratory disease complex-associated pathogens among commercial pig farms in Korea via oral fluid method. J Vet Sci. 2017;18:283-9.

10. Sibila M, Pieters M, Molitor T, Maes D, Haesebrouck F, Segales J. Current perspectives on the diagnosis and epidemiology of Mycoplasma hyopneumoniae infection. Vet J. 2009;181:221-31.

11. Harris R, Marmion BP, Varkanis G, Kok T, Lunn B, Martin J. Laboratory diagnosis of mycoplasma pneumoniae infection.2. Comparison of methods for the direct detection of specific antigen or nucleic acid sequences in respiratory exudates. Epidemiol Infect. 1988;101:685-94.

12. Hurnik D, Dohoo IR, Bate LA. Types of farm management as risk factors for swine respiratory disease. Prev Vet Med. 1994;20:147-57.

13. Stärk K. Epidemiological investigation of the influence of environmental risk factors on respiratory diseases in swine-a literature review. Vet J. 2000;159:37-56.

14. Sørensen V, Ahrens P, Barfod K, Feenstra A, Feld N, Friis N, Bille-Hansen V, Jensen N, Pedersen M. Mycoplasma hyopneumoniae infection in pigs: duration of the disease and evaluation of four diagnostic assays. Vet Microbiol. 1997:54:23-34.

15. Calsamiglia M, Pijoan C, Trigo A. Application of a nested polymerase chain reaction assay to detect Mycoplasma hyopneumoniae from nasal swabs. J Vet Diagn Investig. 1999;11:246-51.

16. Pieters M, Daniels J, Rovira A. Comparison of sample types and diagnostic methods for in vivo detection of Mycoplasma hyopneumoniae during early stages of infection. Vet Microbiol. 2017;203:103-9.

17. Kurth KT, Hsu T, Snook ER, Thacker EL, Thacker BJ, Minion FC. Use of a Mycoplasma hyopneumoniae nested polymerase chain reaction test to determine the optimal sampling sites in swine. J Vet Diagn Investig. 2002;14:463-9.

18. Kim J, Chung HK, Chae C. Association of porcine circovirus 2 with porcine respiratory disease complex. Vet J. 2003;166:251-6.

19. Chae C. Porcine respiratory disease complex: interaction of vaccination and porcine circovirus type 2, porcine reproductive and respiratory syndrome virus, and Mycoplasma hyopneumoniae. Vet J. 2016;212:1-6. 
20. Marois C, Le Carrou J, Kobisch M, Gautier-Bouchardon AV. Isolation of mycoplasma hyopneumoniae from different sampling sites in experimentally infected and contact SPF piglets. Vet Microbiol. 2007;120:96-104.

21. Roos LR, Fano E, Homwong N, Payne B, Pieters M. A model to investigate the optimal seeder-to-naive ratio for successful natural Mycoplasma hyopneumoniae gilt exposure prior to entering the breeding herd. Vet Microbiol. 2016;184:51-8

22. Garcia-Morante B, Segalés J, Fraile L, Pérez de Rozas A, Maiti H, Coll T, Sibila M. Assessment of Mycoplasma hyopneumoniae-induced Pneumonia using Different Lung Lesion Scoring Systems: a Comparative Review. J Comp Pathol. 2016;154:125-34.

23. Pagoto R, Dunlop H, Holyoake T, Gleeson B, Harrison T, Eastaugh M, Fahy T. Evaluation of the extent of Mycoplasma hyopneumoniae shedding from gilts to their progeny in seven $\mathrm{M}$ hyo endemic piggeries in Australia. Proc. ESPHM. 2019:BBD-OP-02.

24. Villarreal I, Vranckx K, Duchateau L, Pasmans F, Haesebrouck F, Jensen JC, Nanjiani IA, Maes D. Early Mycoplasma hyopneumoniae infections in European suckling pigs in herds with respiratory problems: detection rate and risk factors. Vet Med-Czech. 2010;55:318-24.

25. Gardner LA, Willeberg P, Mousing J. Empirical and theoretical evidence for herd size as a risk factor for swine diseases. Anim Health Res Rev. 2002;3:43-55.

26. Pieters M, Eduardo F, Carlos P, Scott D. An experimental model to evaluate Mycoplasma hyopneumoniae transmission from asymptomatic carriers to unvaccinated and vaccinated sentinel pigs. Can J Vet Res. 2010;74:157-60.

27. Pieters M, Pijoan C, Fano E, Dee S. An assessment of the duration of Mycoplasma hyopneumoniae infection in an experimentally infected population of pigs. Vet Microbiol. 2009;134:261-6.

28. Vicca J, Maes D, Jonker L, de Kruif Haesebrouck F. The efficacy of tylosin premix for the treatment and control of Mycoplasma hyopneumoniae infections. Vet Rec. 2005;156:606-10.

29. Fano E, Payne B. Mycoplasma hyopneumoniae gilt acclimation and sow herd stability: essentials to the systematic control approach. AASV Annu Meet. 2015:175-178.

\section{Publisher's Note}

Springer Nature remains neutral with regard to jurisdictional claims in published maps and institutional affiliations.

Ready to submit your research? Choose BMC and benefit from:

- fast, convenient online submission

- thorough peer review by experienced researchers in your field

- rapid publication on acceptance

- support for research data, including large and complex data types

- gold Open Access which fosters wider collaboration and increased citations

- maximum visibility for your research: over $100 \mathrm{M}$ website views per year

At $\mathrm{BMC}$, research is always in progress.

Learn more biomedcentral.com/submissions 